\title{
Sex- related morphometric difference in sternal index and dimensions amongst Nepalese adults
}

\author{
Raj Kumar Karki ${ }^{* 1}$ D, Pankaj Kumar Singh ${ }^{1}$, Subindra Karki' ${ }^{2}$, Dhiraj Kumar Shah ${ }^{1}$ \\ 'Department of Forensic Medicine, ${ }^{2}$ Department of Radiology, Kathmandu University School of Medical Sciences, Dhulikhel, Nepal
}

\begin{abstract}
Introduction: The comprehensive goal in forensic anthropology is the identification of skeletal remains for which researchers are constantly working to produce methods that are as accurate as possible. Because of distinct sexual dimorphism, bones of the pelvis and skull are preferred; however, when these bones are unavailable other bones like sternum have to be used as it holds a great deal of sexual dimorphism. Objective: To evaluate sexual dimorphism in the metric parameters of the sternum through MDCT images amongst Nepalese adults. Materials and Methods: Sternal dimensions of 105 study participants (62 male and 43 female) were measured using Computed Tomography (CT) images from Radiology Department of Dhulikhel Hospital. An independent $t$ test was performed to assess the strength of association between different variables and genders. Differences were considered significant at $P<0.05$. ROC curve analysis was done to determine the discriminating power of variables for sex determination. Result: The different measurements of sternal lengths were significantly greater in male than females $(p<0.001)$ except Sternal Index which was found to be higher in female $(\mathrm{p}<0.001)$. Despite this difference in mean, most of the sterna were in overlapping zone. The limiting point of 126 was determined for total sternum which could correctly classify majority of sternum. Using ROC curve the mesosternum and total sternum were found to be most accurate ( $>95 \%)$ in sex determination. Hyrtl's law could classify $91.9 \%$ of the male and Ashley's rule of 136 could $97.67 \%$ of the female. Conclusion: Hence this study made an effort in sexing the sternum in Nepalese population amongst which mesosternal length and total sterna length were found to be best estimators of sex whereas manubrium length and sternal index were not found to be satisfactory.
\end{abstract}

Key words: Manubrium; mesosternum; overlapping zone; sternal index

\section{Correspondence to:}

Dr Raj Kumar Karki, Associate Professor

Department of Forensic Medicine \& Toxicology

Kathmandu University School of Medical Sciences,

Dhulikhel, Nepal

E-mail: rkkarki17@yahoo.com

Submitted: August 21, 2020

Accepted: October 16, 2020

To cite: Karki RK, Singh P, Karki S, Shah D. Sexrelated morphometric difference in sternal index and dimensions amongst Nepalese adults. JGMC Nepal. 2020;13(2):104-10.

DOI: $10.3126 /$ jgmcn.v13i2.30729

\section{INTRODUCTION}

Identity of a person is important, both in living and dead. ${ }^{1}$ It means finding a set of symptoms that leads to identifying one person from another. ${ }^{2}$ Sometimes experts face a problem even in identifying whether the skeletal remains are of human or not. ${ }^{3,4}$ Identification can become more difficult during mutilation of body parts and decomposition. ${ }^{1,5,6}$ In these cases of dubious identity, fine differences also assume importance and identification has to be done from remnants. ${ }^{5,7}$ Since the bones resist putrefaction and destruction by animals, they are cardinal clue for identification. ${ }^{8-10}$ After ancestry, determination of sex can be undertaken as a prime gravity in identification., ${ }^{1,11-13}$ Unlike stature, sex follows only one direction ${ }^{1}$ and straight away excludes half of the population. ${ }^{8,110}$ steometry is an effective method, preferred with respect to its simple and repeatable processing, low cost, and high accuracy rates ${ }^{7,13,14}$ Nonetheless, morphometric standards cannot be universally applied and standard rules must be implemented for every population and 
region. ${ }^{1,2,4,13,15-19}$ Human biology is simply not amenable to the precision of pure or exact science. ${ }^{1}$ Variability are orchestrated by a complicated interplay of nutritional, environmental and climatic changes. , $7,19^{-19}$

Though, a number of bones such as pelvis, skull, femur etc., have contributed significantly in estimating $\mathrm{sex}^{2,7,10,20}$ in situations when these bones are missing, less sexually dimorphic bones as sternum should be taken. 2,7,9,14,15,21-24 The sternum having a robust structure can survive a great degree of compression and can be procured from cadavers without damage..$^{1,2,5,10,13,18}$ Many researchers have studied sternum in order to prove its usage as an indicator of sex in different populations. ${ }^{1,5,23-26}$ Wenzel(1788)brought some information about sexual dimorphism in the sternum. His work led to Hyrtl's law (1878) which stated if Sternal Index is less than $50 \%$ in males and more than $50 \%$ in females. ${ }^{4,7,25,29}$ Although this law is considered as a rule, there are many studies conducted in different populations, which have proved its unreliability. ${ }^{17,18,26,29}$ Ashley, formulated "The 149 rule" and "The 136 rule" in European and East African population from total sterna length. ${ }^{25}$ Computed virtual models by computed tomography of anatomical structures are proving to be in surge in Medical image data. They can be used to create high-resolution, anatomically accurate 3D models which are close to original bone shape and hence enable rapid measurement. ${ }^{5,7,14,15}$ This is especially important in larger samples, where observer's efficiency and precision decrease while software efficiency increases. ${ }^{10,13}$

Thus, with this study we aim to determine the dimensions and index of the sternum to find out their reliability in sexual dimorphism in the Nepalese population by 3D Computed Tomography and apply Hyrtl's law. To the best of our knowledge, no study so far has assessed sexual dimorphism of the sternum Nepalese populations. This is important since results from other populations cannot be applied to the Nepalese population because of population specificity.

\section{MATERIALS AND METHODS}

All patients who presented to radiology department for thorax CT above 25 years of age according to their physician advice were included in the study for the period of six months. The study was conducted at Department of Radiology, Dhulikhel Hospital after getting approval from Institutional Review Committee, KUSMS with IRC-KUSMS number 75/20. Since we had limited number of bones, virtual models were collected. After excluding patients with sternal deformity, a history of thoracic trauma or surgery, sternal mass, or infiltration, morphometric measurements of the sternum from randomly selected 105 (62 males and 43 females) patients were carried out on MDCT images. No participant was made to undergo a CT scan for the sole purpose of this study. After identification of landmarks, following measurements were done using the inbuilt measurement tool in the software (fig 1 ).

- Length of manubrium (LM): distance between the midpoint of incisurajugularis and midpoint of the manubriosternal joint

- Length of corpus sterni/mesosternum (LB): distance between the midpoint of manubriosternal joint and xiphisternal joint

- $\quad$ Length of totality sternum (LMB): sum of LM and $\mathrm{LB}(\mathrm{LM}+\mathrm{LB})$

- Manubrio corpus index/Sternal index (SI): it is the division of LM by LB, then multiplied by 100 [(LM/LB) $\times 100]$

Rule of 136, given by Ashley (1956) ${ }^{25}$ was applied, which states that if the combined length is more than $136 \mathrm{~mm}$ then it was male and if the value is less than 136 ,it was female sternum. Hyrtl's rule ${ }^{23,25}$ was applied which states that SI $>50$ in female and $<50$ in male. The identification point (IP) ${ }^{20,21,23,26,29}$ was determined by the lowest value of a variable in males and highest value for the same in females. All the values less than the minimum value for the males was treated as female bone and the bones having values more than maximum value of females was treated as male bones. The range between these two values is known as overlapping zone. Variable having a broader overlapping zone is thought to be a bad estimator. The demarking point(DP) ${ }^{20,21,26}$ was calculated by using $\pm 3 S D$ in mean. Mean \pm 3 SD ensured that $99 \%$ of the value fall within the range calculated. The minimum value in males will be taken as demarking point for female i.e. the value less than this point falls in female category. The Limiting Point (LP) ${ }^{21,26}$ was calculated by dividing the sum of male and female identification points by two.

A receiver-operator characteristic (ROC) curve analysis was performed to identify the optimal cut-off points for sternal lengths and sternal index separately at which the sensitivity and specificity are maximum. The area under the curve was also determined for finding the overall accuracy of a variable and its sex discriminating performance.

The data obtained from the study will be analyzed by using Statistical Package for Social Sciences (SPSS/version 25.0). Descriptive analysis was summarized as Mean \pm SD (standard deviation), range ( $\min$ to $\max$ ). Variables were compared by independent Student's $t$ test. The value of $p<0.05$ was considered statistically significant. Data was analyzed for the 
overlapping zone for all the three parameters to determine their reliability in determination of sex.

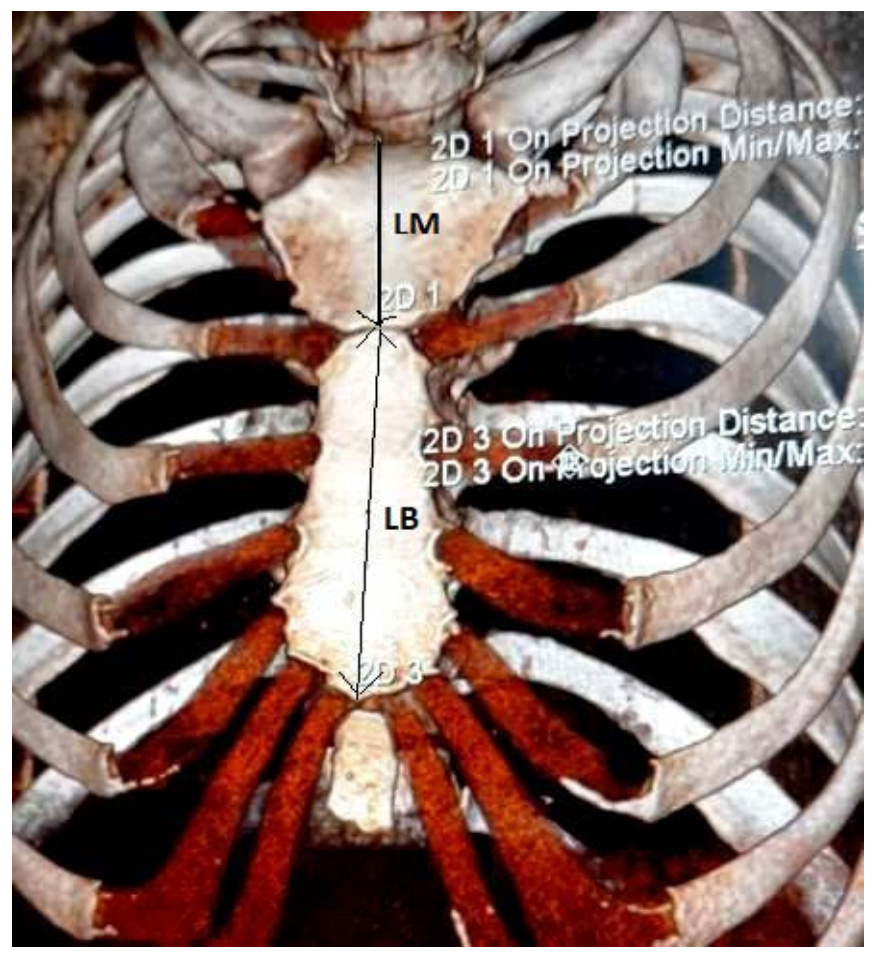

Fig 1: Image (128 slice MD CT Scan) of Chest showing measurements of sternum

\section{RESULT}

Table1: Statistical descriptive of various Sternal Measurements and Index

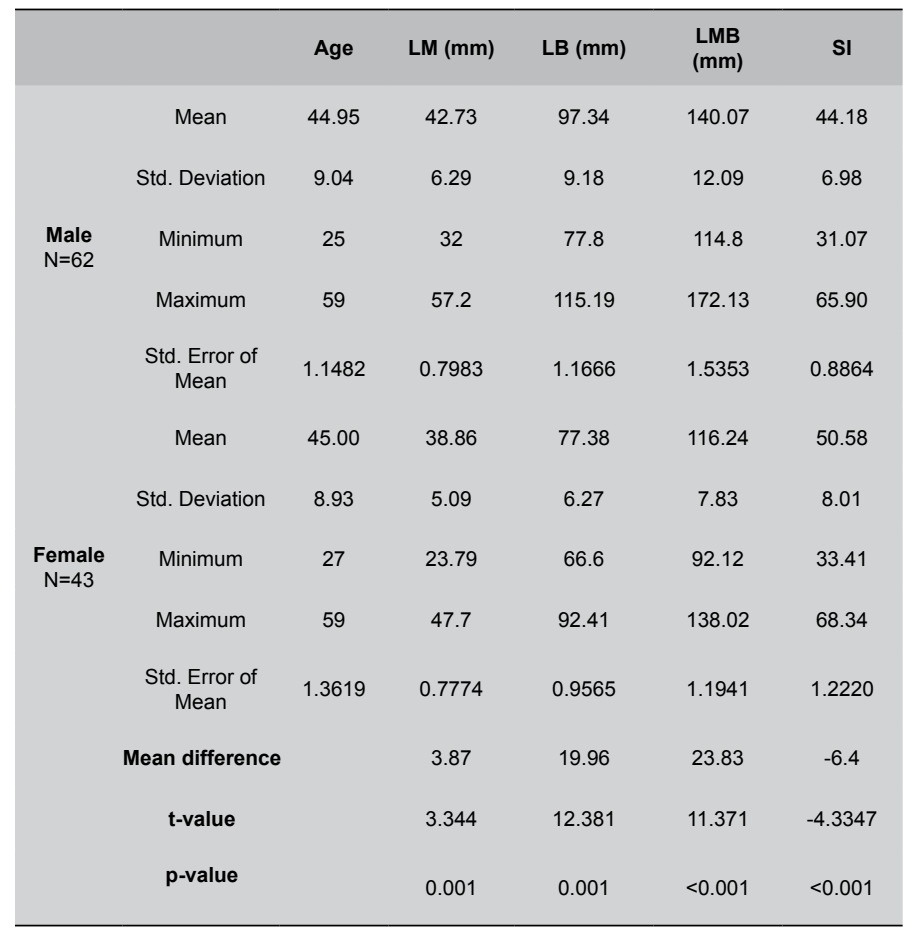

A total of 105 participants above the age of 25 were included in the study. Amongst which 62(59.05\%) were male and
43(40.95\%) were female. The age of the participants ranged from 25 to 59 years. Mean age of male and female participants are shown in Table 1. The descriptive statistics of sternal measurements so that length of the manubrium (LM), length of mesosternum (LB), total length of manubrium and mesosternum (LMB), and calculated sternal index (SI) of both male and female are presented in Table 1. Men had significantly greater lengths of all sternal parameters except sternal index which was greater in females. Difference in the mean of LM,LB, LMB and SI between male and female are $3.87 \mathrm{~mm}, 19.96 \mathrm{~mm}, 23.83 \mathrm{~mm}$ and -6.4 , all of which are highly significant by student's $t$-test for equality of means $(t<0.01)$ (table 1).

Though there was significant difference between the measurements of male and female, there is high percentage of overlapping amongst them (Table 2). Identification Point (IP), Demarking Point (DP) and Limiting Point (LP) were determined and are presented in Table 2. The better estimator was mesosternal length which could classify 41(66.13\%) male and 21(48.84\%) female correctly by using Identification Point. The Identification point of sternal index for male was 33.41 and female was 65.90 , out of which $100 \%$ of female and $93.4 \%$ of female were in overlapping zone. The remaining sterna were in overlapping zone as per identification point. However, the better estimator by using demarking point was total length of manubrium and mesosternum which could correctly classify $27(43.54 \%)$ of male and $14(32.56 \%)$ of female. LM could not be used for sexing both by identification point and demarking point hence is concluded to be least sexually dimorphic. The Limiting Point calculated from Identification point could correctly classify $57(91.93 \%)$ of males and $38(88.37 \%)$ of females by LB correctly and 54(87.09\%) males and 39(90.69\%) females correctly by LMB. It could satisfactorily classify sternums by manubrial length as well. Hence, the Limiting Point can be used reliably in our population for determination of sex.

The optimal values for the discrimination of sex were determined from ROC curve analysis. The different dimensions of sternum showed the sensitivity ranging from $53 \%$ to $92 \%$, specificity ranging from $58 \%$ to $91 \%$, with overall accuracy of $63 \%$ to $96 \%$. The best cut-off values for ML, CL, SL are listed in table 3 above which all sterna are meant to be male and below which all are meant to be female. However for Sternal Index the cutoff value was 48.64, above which all are meant to be female. Mesosternal length showed the best sensitivity and specificity with overall accuracy of 96.5\% (table 3; Fig 2,fig 3). 
Table 2: Sterna falling in Overlapping Zone, Identification, Demarking and Limiting Points

\begin{tabular}{|c|c|c|c|c|c|c|}
\hline \multirow[t]{2}{*}{ Variables } & \multicolumn{2}{|c|}{ LM } & \multicolumn{2}{|c|}{ LB } & \multicolumn{2}{|c|}{ LMB } \\
\hline & Male & Female & Male & Female & Male & Female \\
\hline $\begin{array}{l}\text { Original } \\
\text { Range(mm) }\end{array}$ & $\begin{array}{l}32.0- \\
57.0\end{array}$ & $\begin{array}{l}23.79- \\
47.70\end{array}$ & $\begin{array}{l}77.80- \\
115.19\end{array}$ & $\begin{array}{l}66.60- \\
92.41\end{array}$ & $\begin{array}{l}114.80- \\
172.13\end{array}$ & $\begin{array}{l}92.12- \\
138.02\end{array}$ \\
\hline $\begin{array}{l}\text { Overlapping Zone } \\
\text { by IP(mm) }\end{array}$ & \multicolumn{2}{|c|}{$32.0-47.0$} & $\begin{array}{c}77.80- \\
92.41\end{array}$ & & \multicolumn{2}{|l|}{$\begin{array}{l}114.80- \\
138.02\end{array}$} \\
\hline $\mathbf{I P}(\mathrm{mm})$ & 47.7 & 32 & 92.41 & 77.8 & 138.02 & 114.8 \\
\hline No falling within IP & 15 & 7 & 41 & 21 & 30 & 18 \\
\hline$\%$ classified by IP & 24.19 & 16.28 & 66.13 & 48.84 & 48.38 & 41.86 \\
\hline $\begin{array}{l}\% \text { in overlapping } \\
\text { zone by IP }\end{array}$ & 74.81 & 83.72 & 33.87 & 51.16 & 51.62 & 58.14 \\
\hline $\begin{array}{l}\text { Range by DP } \\
(\text { mean } \pm 3 S D)(m m)\end{array}$ & $\begin{array}{l}23.88- \\
61.59\end{array}$ & $\begin{array}{l}23.57- \\
54.16\end{array}$ & $\begin{array}{l}69.78- \\
124.90\end{array}$ & $\begin{array}{l}58.56- \\
96.19\end{array}$ & $\begin{array}{l}112.44- \\
167.63\end{array}$ & $\begin{array}{l}92.75- \\
139.74\end{array}$ \\
\hline $\begin{array}{l}\text { Overlapping Zone } \\
\text { by } \mathrm{DP}(\mathrm{mm})\end{array}$ & \multicolumn{2}{|c|}{$23.88-54.16$} & $\begin{array}{l}69.78- \\
96.19\end{array}$ & & \multicolumn{2}{|l|}{$\begin{array}{l}92.75- \\
112.44\end{array}$} \\
\hline $\mathrm{DP}(\mathrm{mm})$ & 54.16 & 23.88 & 96.19 & 69.78 & 139.74 & 112.44 \\
\hline $\begin{array}{l}\text { No. classified } \\
\text { by DP }\end{array}$ & 3 & 1 & 26 & 5 & 27 & 14 \\
\hline$\%$ classified by DP & 4.84 & 2.33 & 41.93 & 11.63 & 43.54 & 32.56 \\
\hline $\begin{array}{l}\% \text { in overlapping } \\
\text { zone by DP }\end{array}$ & 95.16 & 97.67 & 58.07 & 88.37 & 56.46 & 67.44 \\
\hline $\mathrm{LP}(\mathrm{mm})$ & \multicolumn{2}{|c|}{39.85} & 85.11 & & \multicolumn{2}{|c|}{126.40} \\
\hline $\begin{array}{l}\text { No classified } \\
\text { by LP }\end{array}$ & 40 & 20 & 57 & & 54 & \\
\hline$\%$ classified by LP & 64.52 & 46.51 & 91.93 & 88.37 & 87.09 & 90.69 \\
\hline
\end{tabular}

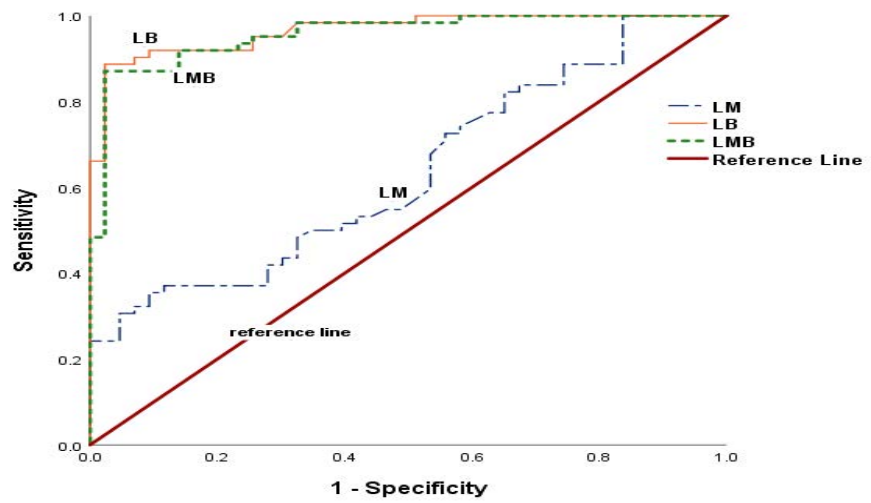

Fig 2: Receiver-operating characteristics (ROC) curves of sternal lengths for sex determination

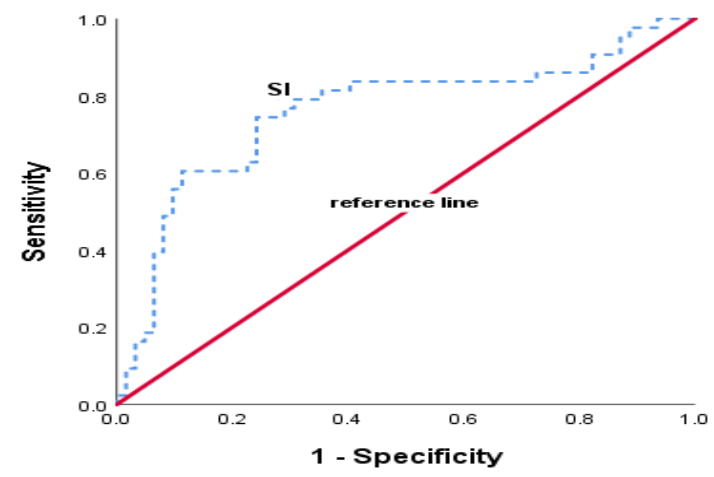

Fig 3: Receiver-operating characteristics (ROC) curve of sterna index for sex determination
Table 3: ROC curve analysis for sternal dimensions

\begin{tabular}{ccccccc}
\hline $\begin{array}{c}\text { Parame- } \\
\text { ters }\end{array}$ & $\begin{array}{c}\text { Cut-off } \\
\text { value }\end{array}$ & AUC & SEE & P & $\begin{array}{c}\text { Sensitiv- } \\
\text { ity } \%\end{array}$ & $\begin{array}{c}\text { Specific- } \\
\text { ity\% }\end{array}$ \\
LM & 40.35 & 0.635 & 0.054 & 0.019 & 53.2 & 58.1 \\
LB & 85.35 & 0.965 & 0.015 & $<0.001$ & 91.9 & 90.7 \\
LMB & 123.435 & 0.956 & 0.018 & $<0.001$ & 91.9 & 86 \\
SI & 48.64 & 0.76 & 0.051 & $<0.001$ & 72.1 & 65.8 \\
\hline
\end{tabular}

(AUC-area under curve, SEE-Standard Error of Estimate)

Table 4: Application of "Rule of 136" and Hyrtl's Law

\begin{tabular}{lcc}
\hline & Male & Female \\
Actual number & 62 & 43 \\
By Ashley's rule of 136 & 41 & 64 \\
No. correctly classified & 40 & 42 \\
\% correctly classified & 64.52 & 97.67 \\
By Hyrtl's law & 74 & 31 \\
No. correctly classified & 57 & 26 \\
\% correctly classified & 91.9 & 60.5 \\
\hline
\end{tabular}

Table 5: Comparison of mean values of current study with different populations

\begin{tabular}{|c|c|c|c|c|c|c|}
\hline Author & $\begin{array}{l}\text { Popula- } \\
\text { tion }\end{array}$ & Sex & LM & LB & LMB & SI \\
\hline \multirow[t]{2}{*}{ Ashley ${ }^{25}$} & \multirow[t]{2}{*}{ European } & M & 52.2 & 104.7 & 156.9 & - \\
\hline & & $\mathrm{F}$ & 47.9 & 90.8 & 138.7 & - \\
\hline \multirow{2}{*}{$\begin{array}{c}\text { Dahiphale } \\
\text { et al }{ }^{29}\end{array}$} & \multirow{2}{*}{$\begin{array}{l}\text { Indian Ma- } \\
\text { harastra }\end{array}$} & M & $48.46 \pm 5.58$ & $94.43 \pm 9.52$ & $142.19 \pm 11.29$ & $51.99 \pm 8.34$ \\
\hline & & $\mathrm{F}$ & $43.78 \pm 5.24$ & $70.19 \pm 8.54$ & $113.87 \pm 12.02$ & $63.01 \pm 8.51$ \\
\hline \multirow{2}{*}{$\begin{array}{l}\text { Chowdhuri } \\
\text { et al }{ }^{5}\end{array}$} & \multirow{2}{*}{$\begin{array}{l}\text { Indian } \\
\text { Calcutta }\end{array}$} & M & $48.22 \pm 5.17$ & $87.84 \pm 11.78$ & - & $56.10 \pm 10.25$ \\
\hline & & $\mathrm{F}$ & $44.15 \pm 5.25$ & $71.22 \pm 11.17$ & - & $63.11 \pm 9.33$ \\
\hline \multirow{2}{*}{$\begin{array}{c}\text { Toneva et } \\
\text { al }^{18}\end{array}$} & \multirow{2}{*}{ Bulgarian } & M & $53.7 \pm 5.1$ & $107.5 \pm 10.9$ & - & $50.4 \pm 6.8$ \\
\hline & & $\mathrm{F}$ & $47.3 \pm 3.6$ & $88.1 \pm 8.7$ & - & $54.0 \pm 5.3$ \\
\hline \multirow{2}{*}{ Tun et $\mathrm{al}^{6}$} & \multirow{2}{*}{ Thai } & M & $48.04 \pm 4.55$ & $98.12 \pm 9.1$ & $146.20 \pm 9.64$ & $49.06 \pm 6.4$ \\
\hline & & $\mathrm{F}$ & $44.32 \pm 4.2$ & $83.08 \pm 6.09$ & $126.87 \pm 6.65$ & $53.10 \pm 6.55$ \\
\hline \multirow{2}{*}{$\begin{array}{l}\text { Ekizoglu } \\
\text { et al }^{10}\end{array}$} & \multirow{2}{*}{ Turkish } & M & $52.5 \pm 5.2$ & $104.9 \pm 10.6$ & - & $50.7 \pm 9.5$ \\
\hline & & $\mathrm{F}$ & $48.2 \pm 4.5$ & $89.1 \pm 9.2$ & - & $54.7 \pm 8.1$ \\
\hline \multirow{2}{*}{ Mittal et al ${ }^{26}$} & \multirow{2}{*}{$\begin{array}{l}\text { Indian } \\
\text { Haryana }\end{array}$} & M & $48.94 \pm 4.70$ & $93.07 \pm 13.40$ & - & $53.69 \pm 9.88$ \\
\hline & & $F$ & $45.42 \pm 5.0$ & $74.71 \pm 9.00$ & - & $61.56 \pm 9.62$ \\
\hline \multirow{2}{*}{$\begin{array}{l}\text { Macaluso } \\
\text { et al }{ }^{19}\end{array}$} & \multirow{2}{*}{ Spanish } & $M$ & $51.85 \pm 4.74$ & $106.25 \pm 11.05$ & $158.10 \pm 12.70$ & $49.22 \pm 6.06$ \\
\hline & & $\mathrm{F}$ & $45.85 \pm 4.76$ & $87.77 \pm 9.61$ & $133.62 \pm 11.22$ & $52.80 \pm 7.59$ \\
\hline \multirow{2}{*}{$\begin{array}{l}\text { Gupta et } \\
\text { al }^{11}\end{array}$} & \multirow{2}{*}{$\begin{array}{l}\text { Indian } \\
\text { Delhi }\end{array}$} & M & 40.64 & 87.31 & 127.95 & 46.81 \\
\hline & & $\mathrm{F}$ & 37.28 & 81.57 & 120.09 & 46.18 \\
\hline \multirow{2}{*}{$\begin{array}{l}\text { Changani } \\
\text { et } \mathrm{al}^{20}\end{array}$} & \multirow{2}{*}{$\begin{array}{l}\text { Indian } \\
\text { Kerala }\end{array}$} & M & $45.6 \pm 6.7$ & $92.49 \pm 10.72$ & $138.10 \pm 11.63$ & $50.15 \pm 10.69$ \\
\hline & & $\mathrm{F}$ & $40.22 \pm 6.53$ & $75.89 \pm 8.66$ & $116.11 \pm 11.08$ & $53.72 \pm 10.69$ \\
\hline \multirow{2}{*}{$\begin{array}{l}\text { Present } \\
\text { Study }\end{array}$} & \multirow{2}{*}{ Nepalese } & M & $42.73 \pm 6.29$ & $97.34 \pm 9.18$ & $140.07 \pm 12.09$ & $44.18 \pm 6.98$ \\
\hline & & $\mathrm{F}$ & $38.86 \pm 5.09$ & $77.38 \pm 6.27$ & $116.24 \pm 7.83$ & $50.58 \pm 8.01$ \\
\hline
\end{tabular}

Ashley's"rule of 136" using total manubrium and mesosternum length (LMB) was applied in our study participants which could correctly classify most of the 
females so that $42(97.96 \%)$, however only $40(64.2 \%)$ of male were correctly classified. Regarding Hyrtl's law applicability, it could correctly classify 57(91.9\%) of the male and only 26 (60.5\%) of female. By "trial and error" we applied the rule of 126 in our study population which could correctly classify 87.09\% male and $90.69 \%$ female.

\section{DISCUSSION}

Many authors have studied sternum for estimation of sex by using dry bones. ${ }^{1,6,12,17,23,29}$ However, current study and various other authors have tried to use morphometric analysis for studying the variations in sternum with MDCT as it generates images close to original bone shape and allows rapid measurement in any axis. ${ }^{5,10,13,14,15}$ Though morphometric analysis can be done effectively with CT scans, certain measurement errors might occur due to orientation. ${ }^{14}$ In the present study various lengths of sternum and sternal index has been used for determining the sexual dimorphism however, other measurements like width, length of xiphoid process, sternal area etc were included by various researchers with varying degree of accuracy. 2,8,10,14,15,19-21,29

It is obvious from our study as well as various other studies done in different population that all sternal parameters have significantly higher value in male than in female showing sexual dimorphism both in dry sterna or from CT scans as shown in Table 5. The length of the sternum showed bigger difference in comparison with European population than with Asian population as well as amongst close population which have been compared in Table 5. However, sternal index was significantly greater in female than in male which was not agreed by some authors. ${ }^{11,20}$ The greater sternal index in female is attributed to the fact that LM in female exceeds half the LB, whereas in males LB is at least twice the LM as seen in our study and various other studies. ${ }^{1,10,18,20}$ However, this was not agreed by other researchers. ${ }^{8,19}$ The manubrium length was shorter in our study population than the various other populations around the world (Table 5). It may be due to the difference in nutrition, geography, genes and environment amongst the different population. ${ }^{6,15,18-21}$ Various values were determined for the correct classification of sternum like Identification Point, Demarking Point and Limiting Point. The best amongst these estimators was in our study was found to be Limiting Point which could satisfactorily classify the sternum whereas Identification Point and Demarking Point failed to classify most of the sternums. Most of them have fallen into the overlapping zones or range of the other sex in our study. This was consistent with the other studies. ${ }^{4,8,26}$ Hence we would like to advocate for not using demarking point as a tool for sex determination in our population. This observation was agreed with Singh et al ${ }^{21}$ who also found
IP to be the satisfactory estimator and demarking point to be the least reliable estimator for various lengths. Manubrial length was found to be the least accurate for determining sex by using IP, DP and LP and other methods which was concurrent with other studies as most of the sterna fell into the range of other sex. ${ }^{4,6,17,20,29}$ The most accurate dimension being mesosternal length and total length by IP and LP in our study which corroborated with some ${ }^{19,20,26,29}$ but was disagreed with others. ${ }^{4,11}$

Ashley's rule of 136 used for East African's could classify $76.7 \%$ male and $80.4 \%$ female in their study. ${ }^{25}$ We applied same rule in our study population which could classify majority $42(97.67 \%)$ of females but only $40(64.52 \%)$ of males. This was very close to the finding of Adhvaryu et al ${ }^{4}$ who also observed $71.11 \%$ male and $96.34 \%$ female obeying the rule.Dahiphale et $\mathrm{al}^{29}$ applied rule of 129 for North Indian population by which he could classify $91.66 \%$ male and $82.97 \%$ female. Atesoglu et al $^{15}$ formulated rule of 144 for Turks which could correctly classify most of the genders. The Limiting point of 126 was applied in our population which could be successfully applied in our population and classified $87.09 \%$ of males and $90.69 \%$ of females. However it can't be said if any particular sternum given is definitely male or female by these rules. ${ }^{2,9}$

The sternal index of female was significantly greater than the male in our study. However few authors found no significant difference between the SI of two sexes as both of the values were close and above fifty. ${ }^{2,14}$ The sternal index of one sex had fallen within the range of other sex making determination of sex difficult as (100\% female and $93.4 \%$ of male) which corroborated with other study ${ }^{18,29}$ Hyrtl's law for SI was also applied in our study population. It could classify majority of male $57(91.9 \%)$ of male and $26(60.5 \%)$ of female. This result was is close agreement with other studies in which $60-80 \%$ of female sterna obeyed the rule ${ }^{15,18,24,25}$ but was farther from the finding of other authors that showed 90$100 \%$ female sterna obeying the rule. ${ }^{23,26,29}$ For male our result was in disagreement with many studies which were not satisfactorily (30-60\%) classified by this rule 15,18,22,23,25,29 but was close with Atal et $\mathrm{al}^{24}$ where $89.28 \%$ male sterna obeyed the rule. Again these variations in the values can be attributed to differences in nutrition, race and geography amongst the population.

ROC curve analysis was done on variables to see their discriminating power. Various cut-off values were determined which showed high sensitivity and specificity for mesosternum (LM) and total sternum (LMB) with high overall accuracy $>95 \%$. Hence, can be used as best predictive factors of sex in our population. This result corroborated 
with other study by several researchers showing $>85 \%$ overall accuracy which also showed optimum sensitivity and specificity for mesosternal length. ${ }^{10,14,27}$ However our study showed less sensitivity and specificity for sternal index and manubrium length with overall accuracy of $63.5 \%$ and $76 \%$ respectively. This was approximate to the result of other studies by Ekizoglu et $\mathrm{al}^{10}$ and Yongue et $\mathrm{al}^{27}$ but disagreed with few others ${ }^{2,8,14}$ who showed good accuracy with manubrium length. Many authors using discriminate function analysis also found mesosternal length and total length to be highly sexually dimorphic. .,6,10,19,28 $^{2}$

It should be noted that bones are population specific and various factors could cause variations on the phenotype of population even amongst close population..$^{5,18,19}$

\section{CONCLUSION}

Hence, we demonstrated the metric features of sterna of Nepalese population in current study. We conclude that we can satisfactorily determine gender by using the sternal measurement like mesosternal length and total sterna length but we found sternal index and manubrium length less satisfactory. We used the rule of 126 for total length of manubrium and mesosternum for Nepalese population which could correctly sex majority of the sternum. We would like to emphasize the researchers to do additional study utilizing much larger sample and from other geographical region of Nepal to validate the result of this study using other parameters of sterna.

\section{REFERENCES}

1. Manoharan C,Jeyasingh $\mathrm{T}$, Dhanalakshmi V, Thangam D. Is Human Sternum a Tool for Determination of Sex? Ind J Forensic and ComMed. 2016;3(1):60-3. DOI: 10.5958/2394-6776.2016.00009

2. Soltani S, Aghabiklooei A, Ameri M, Memarian A, Nikanzad A. Gender Identification Based on the Parameters of the Sternum Bone in the Cadavers. International Journal of Medical Toxicology and Forensic Medicine. 2020; 10(1):26740. DOI:10.32598/ijmtfm.v10i1.26740

3. Jaiswal R. Determination of age by human sternum. Int J Anat Res. 2018;6(3.2):5525-30.DOI: 10.16965/ ijar.2018.270.

4. Adhvaryu AV, AdhvaryuAM, Rathod S P, Chauhan P R, Joshi H G. A study of sexual dimorphism in human sterna.Int J Med Res Health Sci. 2013;2(3): 577-81. DOI:10.5958/j.2319-5886.2.3.10

5. Chowdhuri S, Roy P, Dey A, Das S, Ghosh R. A Study for Determination of Sex by Multidetector Computed
Tomography of Sternum using Discriminant Function and Logistic Regression. Arab J Forensic Sci\& Forensic Med. 2019;1(10):1445-54.DOI:10.26735/16586794.2019.035

6. Tun SM ,Das S, Ruengdit S, Singsuwan P, Mahakkanukrauh P. Sex determination from different sternal measurements: a study in a Thai population. J Anat Soc Ind. 2015;64:15561. DOI:10.1016/j.jasi.2015.10.004 0003-2778

7. Tuncer I. Sternal morphometry comparison to chest measurements and using roentgenography.Int J Med and Health Res. 2019; 5(11): 142-46.

8. Gupta M, Kumar A, Khanna SK. Determination of Sex from sternal bone in Central Delhi Population. J Indian Acad Forensic Med. 2014;36(3):234-37.

9. Changani MV, Chudasama J, Talsaniya D, Vadgama J, Thummar B, Singel TC. Determination of sex from the width and the area of human sternum \& manubrium in Gujarat population. J Res Med Den Sci 2014;2(3):13-8. DOI : $10.5455 /$ jrmds.2014234

10. Ekizoglu O, HocaogluE ,Inci E, Bilgili MG, Solmaz D, Erdil I, Can IO. Sex Estimation From Sternal Measurements Using Multidetector Computed Tomography.Medicine. 2014;93(27):e240. DOI: 10.1097/ MD.0000000000000240 PMID: 25501090

11. Gupta VP, Shah AH. "Sex Determination of Nepalese Medical Students of NAIHS-COM by using Foot Index Method". Acta Scientific Med Sci.2018;2(2):8-11.

12. Akshayaa L,Sangeetha S, PremavathyD.Quantitative analysis of indices of the Sternum for sexual dimorphism. Drug Invention Today. 2019;12(4):768-70.

13. Bedalov A, Basic Z, Marelja I, Dolic K, Bukarica K, Missoni $S$ et al.Sex estimation of the sternum by automatic image processing of MSCT images. Croat Med J. 2019;60:237-45. DOI:10.3325/cmj.2019.60.237

14. Oner Z, Oner S, Kurtul I, Sahi B. Usage length of sternum components and sternal angle through images obtained by computerized tomography image reconstruction in gender determination. Ann Med Res. 2019;26(2):217-21. DOI: 10.5455/annalsmedres.2018.11.257

15. Atesoglu S, Deniz M, Uslu A I. Evaluation of the morphological characteristic and sex differences of sternum by multi-detector computed tomography. Folia Morphol. 2018;77(3):489-97. DOI: 10.5603/ FM.a2018.0002

16. Romao MO, Rossi WC, CorsiniW, Moraes LHR, Fernandes GJM, Nogueira DA, Esteve A.Anthropometric Study of 
Human Hip Bones of Southern Brazilians by Rabbi Method. Braz J Forensic Sci Med Law Bioethics. 2020;9(3):356-65. DOI:10.17063/bjfs9(3)y2020356

17. Osunwoke EA, Gwunireama IU, Orish CN, et al. A study of sexual dimorphism of the human sternum in the southern Nigerian population. J Appl Biosci. 2010; 26:1636-9.

18. Toneva DH and Nikolova SY.Reliability of the Sternal Index as a sex indicator in medieval skeletal remains from Northeastern Bulgaria.J. BioSci. Biotech. 2014; SE:e 149e152.

19. Macaluso PJ andLucena J. Estimation of sex from sterna dimensions derived from chest plate radiographs in contemporary Spaniards. Int J Legal Med.2014; 128(2):389-95. DOI 10.1007/s00414-013-0910-z

20. Changani MV, Javia MD, Varma KA. Determination of sex from various measurements of human sternum \& manubrium in Gujarat population. J Res Med Den Sci. 2014;2(1):59-65. DOI: 10.5455/jrmds.20142111

21. Singh J, Pathak RK, SinghD. Morphometric sex determination from various sternal widths of Northwest Indian sternums collected from autopsy cadavers: a comparison of sexing methods. Egy J Forensic Sci. 2012;2(1):18-28. DOI:10.1016/j.ejfs.2011.12.002.

22. Sharma SV, Atam V, Kumar N, Sharma N, Atam I, Sharma HB. Study of gender determination in living adult male and female subjects by evaluating the size of sternum about north Indian population. Indian J Anat Surg Head Neck Brain. 2018;4(4):118-22. DOI: 10.18231/25815229.2018 .0031

23. Kaneriya D, Suthar K, Patel V, Umarvanshi B, Mehta C, Tailor C. Morphometric study of sternum for determination of sex. Cibtech J Bio-Protocols. 2013; 2 (2):6-13 . Corpus ID: 45099123

24. Atal DK ,Murari A, Naik SK. Role of Sternal Index in Determination of Gender. Ind J Forensic Med Pathol. 2008;1(3 \& 4):71-4.

25. Ashley GT. The human sternum-the influence of sex and age on its measurement. J Forensic Med. 1956;3:27-43.

26. Mittal P,Khanagwal VP, Paliwal PK. Sternum as an indicator of sex in haryanvi population of India: A morphometric analysis.J Punjab Acad Forensic Med Toxicol. 2014;14(2):76-81

27. Yongue GN, Kurtulus A, Bayazit O, Adiguzel E, UnalI , Demir S, Acar K. Estimation of stature and sex from sternal lengths:an autopsy study. AnatSci Int. 2014;90:89-96. DOI 10.1007/s12565-014-0235-0

28. Mittal P, Khanagwal VP, Paliwal PK. Reliability of Sternal Index in Sexual Dimorphism In the Haryanvi Population of India.J Indian Acad Forensic Med. 2014;36(2):133-6.

29. Dahiphale VP, Baheete BH, Kamkhedkar SG. Sexing the human sternum in Marathwada Region. J Anat Soc India. 2002;51:162-7. 